\title{
The Islamic tradition and health inequities: A preliminary conceptual model based on a systematic literature review of Muslim health-care disparities
}

\author{
Aasim I. Padela, Danish Zaidi
}

Department of Medicine, The University of Chicago, Chicago, IL, ' Wake Forest School of Medicine, Winston-Salem, NC, USA

\begin{tabular}{|c|}
\hline Access this article online \\
\hline Website: www.avicennajmed.com \\
\hline DOI: 10.4103/ajm.AJM_134_17 \\
\hline Quick Response Code: \\
\hline \\
\hline
\end{tabular}

\begin{abstract}
Objective: The objective of this study was to identify mechanisms by which Islamic beliefs, values, and Muslim identity might contribute to health inequities among Muslim populations. Methods: A systematic literature review of empirical studies in Medline from 1980 to 2009 was conducted. The search strategy used three terms covering health-care disparities, ethnicity, and location to uncover relevant papers. Results: A total of 171 articles were relevant based on titles and abstracts. Upon subsequent full-text review, most studies did not include religious identity or religiosity as explanatory variables for observed health disparities. Of 29 studies mentioning Islam within the text, 19 implicated Muslim identity or practices as potential explanations for health differences between Muslim and non-Muslim groups. These 19 studies generated six mechanisms that related the Islamic tradition, Muslim practices, and health inequities: (1) Interpretations of health and/or lack of health based on Islamic theology; (2) Ethical and/or cultural challenges within the clinical realm stemming from Islamic values or practices; (3) Perceived discrimination due to, or a lack of cultural accommodation of, religious values or practices in the clinical realm; (4) Health practices rooted within the Islamic tradition; (5) Patterns of health-care seeking based on Islamic values; and (6) Adverse health exposures due to having a Muslim identity. Conclusion: While there is scant empirical research on Muslim health-care disparities, a preliminary conceptual model relating Islam to health inequities can be built from the extant literature. This model can serve to organize research on Muslim health and distinguish different ways in which a Muslim identity might contribute to the patterning of health disparities.
\end{abstract}

Key words: Conceptual model, health-care disparities, health-care inequality, minority health, religiosity

\section{INTRODUCTION}

Systematic health differences between ethnic/racial minority groups and majority groups in high-income contexts have been noted since the emergence of quantitative measures of population health. ${ }^{[1-3]}$ Many of these health disparities persist even after adjusting for markers of health-care access. Further, these inequities cut across diverse health outcomes in North America, including differences in preterm birth,

Address for correspondence: Dr. Aasim Padela, Department of Medicine, University of Chicago, 5841 South Maryland Avenue, MC 6092 Chicago, IL 60637,USA.

E-mail: apadela@uchicago.edu infant mortality, child mortality, heart disease, cancer, and overall mortality. ${ }^{[4-9]}$

Beyond socioeconomic differences and differential health-care access between minority and majority groups,

This is an open access article distributed under the terms of the Creative Commons Attribution-NonCommercial-ShareAlike 3.0 License, which allows others to remix, tweak, and build upon the work non-commercially, as long as the author is credited and the new creations are licensed under the identical terms.

For reprints contact: reprints@ @edknow.com

Cite this article as: Padela Al, Zaidi D. The Islamic tradition and health inequities: A preliminary conceptual model based on a systematic literature review of Muslim health-care disparities. Avicenna J Med 2018;8:1-13. 
explanatory mechanisms for ethnic and racial differences in health have included differences in physiology, exposure to discrimination and bias, and acculturative stress. ${ }^{[3,10-16]}$ Although controversial, differences in genetic predisposition also explain differences in population health metrics. ${ }^{[3,17]}$ More relevant to the present study is research that implicates culturally informed preferences and values as mediators of ethnic and racial differences in health. ${ }^{[3]}$ For example, the regular chewing of Betel quid is believed to contribute to oral and oropharyngeal cancers among Southeast Asians. ${ }^{[18]}$

While ethnic and racial differences in health are well documented in the health literature, differences in health indicators by religion remain understudied. However, similar to ethnicity and culture, religion can be an important determinant of health outcomes and warrants explicit attention in public health work. Indeed, religion may substantially shape the perceptions, attitudes, beliefs, and behaviors of individuals toward their health, both within and outside of the health-care system. In interactions within the health-care system, religion may inform expectations from health-care providers, guide medical decision-making, and influence adherence to medical treatment. ${ }^{[19-22]}$ Thus, for some patient populations, religion can serve as an alternative entry point beyond the biomedical model for developing and articulating meanings of health, understanding health practices, and actively participating in health-care choices. ${ }^{[23]}$ Religion and spirituality also have direct effects upon mental and physical health, as they influence coping strategies and health behaviors, which in themselves create differential health risks or ameliorate the burden of disease. ${ }^{[24-26]}$

Muslim Americans represent a community that is ethnically and racially diverse yet is bound by a shared religious tradition that shapes their health behaviors and health-care experiences. An average estimate of Muslims in the US is 5.4 million, with sources suggesting a range of 3.4 million to 7 million. ${ }^{[27-30]}$ Within North America, Canadian Muslim population number around 650,000, and Muslims in Mexico are noted to be 110,000 persons. ${ }^{[31]}$ Major ethnic subgroups comprising the American Muslims include indigenous African-Americans, South Asian Americans, and Arab-Americans. ${ }^{[32]}$ Although American Muslims come from diverse ethnic backgrounds, their religion serves as a unifying cultural dimension. Consequently, many aspects of health may be informed by the practice of Islam - from conceptions of disease and cure to interactions that Muslim patients have with the health-care system.

Systematic quantitative research on the intersection of Islamic values, Muslim practices, and health has been hampered by the fact that most national health databases and surveys do not capture religious affiliation, thus precluding analyses by religion. Furthermore, naming algorithms and ethnic and racial affiliation as proxies for religious identification with Islam have not proven practical. ${ }^{[33]}$ Thus, much of what is accessible in the health literature about the influence of Islamic beliefs and/or practices on American Muslim health has been documented through qualitative studies focusing on specific subgroups within the population and expert commentaries.

This literature has suggested that Muslim practice may both hinder and enable good health. ${ }^{[34]}$ For example, Ramadan fasting and the performance of the Hajj (pilgrimage to Mecca) may pose health risks, while Islamic injunctions against sexual promiscuity and imbibing alcohol, as well as a recommendation against smoking, may promote health. ${ }^{[19-21,35]}$ Similarly, Islamic ethics, on one hand, have been suggested to present challenges in health-care delivery through a preference for same-sex providers, which may link to poorer preventive health care seeking. ${ }^{[22,36,37]}$ Yet on the other hand, these values may aid providers in promoting health through the support of genetic testing and family planning. ${ }^{[38-40]}$ Some studies have suggested that Muslims view God as the one who ultimately controls health and illness, and He provides the cure. ${ }^{[41,42]}$ For example, ritual prayers, supplication, and reading of the Qur'an are seen to have health benefits and may be utilized as primary sources of healing, or as complementary to allopathic medicines. ${ }^{[20,43]}$ Given these complex views and practices, Islamic practices may produce expectations and norms that may not be adequately met by the health-care system. ${ }^{[44,45]}$

Given the disparate views on the interplay between Islamic values, Muslim practices, and health inequities, as well as a paucity of frameworks by which to understand the influence of religion on health more broadly, this work sought to use the extant health literature and build a conceptual model to understand how Islamic beliefs, values, practices, and a Muslim identity might contribute to health inequities among Muslim Americans.

\section{METHODS}

We conducted a Medline search using both PubMed and Ovid portals aimed at identifying empirical studies of health among North American Muslim populations between January 1980 and May 2009. Our search strategy employed three terms covering the domains of health-care disparities, ethnicity, and location. All searches were limited to the English language.

For Ovid, the health-care disparities term contained the exploded items: "Health Status Disparities OR Healthcare 
disparities OR Minority Health OR Delivery of Healthcare OR Health Services Accessibility OR Morbidity OR Incidence." The ethnicity domain within Ovid phrase included national identities from Muslim majority nations (as defined by the Pew Research Center), and also Ba-Yunus' aforementioned ethnic identities associated with Islam. Examples included "AND Arab" or "AND Indonesia." The third location term used was "AND America."

The PubMed search strategy utilized the Ovid search terms and the additional MeSH terms "Epidemiology OR Neoplasms OR Cardiovascular System OR Prevalence" for the health-care disparities' domain. The same ethnicity and location terms as in the Ovid search strategy were used for PubMed.

After concluding these database searches, a group of four researchers reviewed titles and abstracts and retained pertinent articles for further full-text review. The criterion for pertinence was as follows: the article must deal with North America and a Muslim majority ethnic identity in either its title or abstract. The two most frequently appearing journals, Journal of Immigrant and Minority Health and Ethnicity and Disease, were then hand searched from 2001 to 2009 for further articles not identified by the search string and any additional pertinent articles were kept for full-text review.

Three investigators independently used a standard evaluation and data abstraction form in reviewing each article. Articles were screened by the type of study, ethnicity, disease state studied, health inequity mechanism, and mention of Islam as a pathway in the production of health. Discrepancies among the three reviewers were resolved by team consensus during face-to-face meetings.

For the purposes of this review, we differentiated between Islam as a religious tradition, Muslim behaviors, and Islam as a religious identity (i.e., being a Muslim). Islam as a religious tradition incorporates scripture and sources, and the values derived thereof. These teachings prescribe Islamic practices or values such as prayer or modesty, respectively. Variably the religion then informs Muslim behaviors. Given that Islam is an important (but not independent) influence on Muslim behaviors, certain behaviors and practices of Muslim peoples may not necessarily be religiously derived. Lastly, Muslim identity, independent of Muslim behaviors, was also considered, as it may imply exposures that influence health.

In the next section, we report on manuscripts that mentioned Islamic practice and Muslim behaviors as potential pathways for health inequities between North American Muslims and the general population in order to develop a conceptual model. General trends from our literature review are published elsewhere. ${ }^{[46]}$

\section{RESULTS}

Out of 6010 articles uncovered by the search string, 171 articles underwent full-text review. Of these 171 studies, 29 specifically mentioned Islam and only 19 implicated Muslim identity and/or practice as mechanistic influences that could produce health differences between Muslim and non-Muslim groups [Table 1].

These 19 papers utilized qualitative methods, predominantly assessed single ethnic groups located within a specific geographic region of North America, and used convenience or purposive sampling. Yet they yielded six principle means by which Islamic values and Muslim practices may produce health inequities between North American Muslims and the general population [Figure 1]. These are:

1. Interpretations of health and/or lack of health based on Islamic theology

2. Ethical and/or cultural challenges in the clinical realm stemming from Islamic values or practices-these are clinical care challenges or ethical dilemmas confronting health-care practitioners as a result of Muslim patient values and beliefs

3. Perceived discrimination due to, or a lack of cultural accommodation of, religious values or practices in the clinical realm - this category includes responses of the health-care system to Islamic values and practices that are perceived to be discriminatory by Muslim patients, or demonstrate a lack of accommodation of Muslim patient values

4. Health practices rooted within the Islamic tradition - these are health behaviors derived from Islamic teachings and texts

5. Patterns of health care seeking based on Islamic values - this domain encompasses Islamically derived influences on the type of, and the timing when, allopathic health care is sought

6. Adverse health exposures due to having a Muslim identity - these include health risks posed by a Muslim identity prior to entering the health-care system.

\section{Interpretations of health and/or lack of health based} on Islamic theology

Several studies suggest that the incorporation of a religiously informed view of disease causation, or meanings of health and its absence, may influence health outcomes among Muslims. Mechanistically, these interpretations influence 


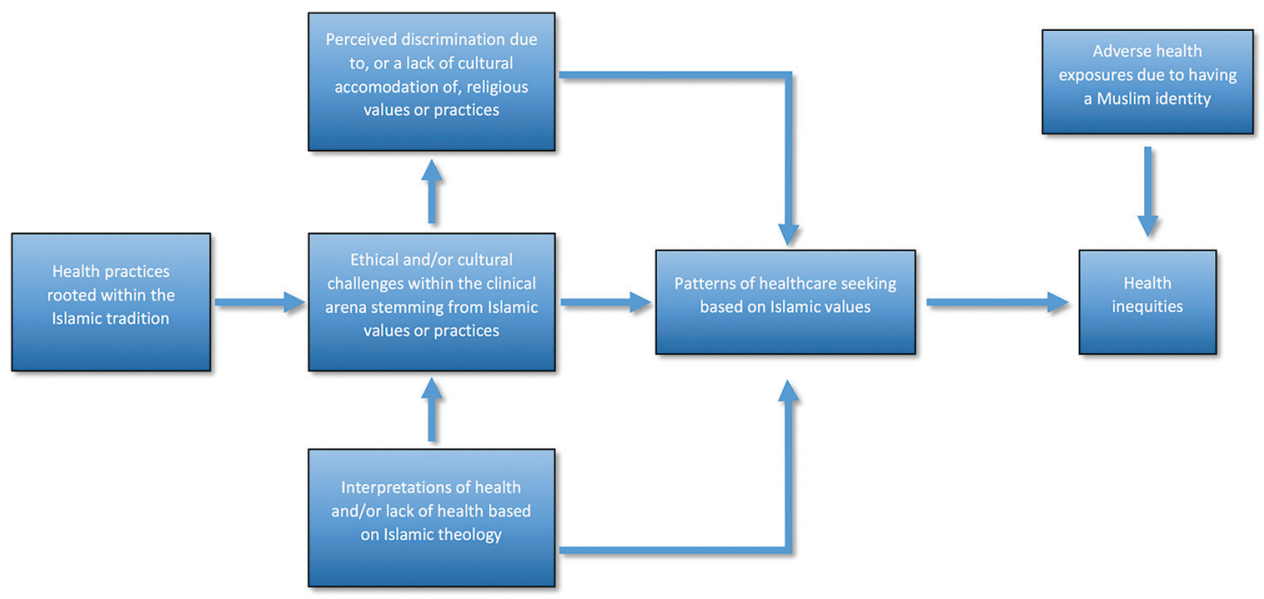

Figure 1: Mechanisms through which Islamic identity might contribute to health inequities. Our model attempts to link Islam to health inequities. The social determinants of health are of great importance in assessing health differences and should be accounted for when considering population health

health differences through health and health care-seeking behavior, and can lead to cultural or ethical challenges in the clinical realm.

For example, in a study of Somali women receiving prenatal care in San Diego, respondents noted that pregnancy was viewed as a "blessing from God." This view implicated a clinical obstacle for providers as patients "did not favor contraceptive advice or practice(s)," and the belief thus impacted health care-seeking behaviors. ${ }^{[4]}$ In another study, immigrant Pakistani families' conceptions of health were reported to include social and spiritual, as well as physical domains. Thus, their acceptance of medical treatments was mediated by a sense of concordance with their perception of which part of their health was ailing. ${ }^{[43]}$ In a similar fashion, Afghan-American elders residing in California reported health to be related to their adherence with Islamic religious rituals and religious guidelines, consequently they utilized a variety of religious practices, for example, prayer, as a means for healing. ${ }^{[48]}$

The influence of "fatalistic" views upon cancer screening was also found among American Muslims. Johnson et al. explored South Asian women's views on breast health practices and breast cancer. Some respondents in their sample viewed breast cancer to be a "disease of fate," thereby influencing their health care-seeking patterns. These women believed that they were destined to suffer; others felt that their fate could be changed through prayer and medical care. ${ }^{[41]}$ Arab-American immigrants in New York echoed the belief that cancer was "from God" and that modifiable risk factors were secondarily implacable. Some respondents in this sample further interpreted cancer as a punishment from God for their religious failings. Such views may be linked to fatalistic practices toward cancer within the American
Muslim community, complicating health care-seeking behaviors and influencing attitudes toward cancer treatment. For example, these views could be linked to lower rates of screening and protracted healthcare seeking. ${ }^{[49]}$ In a separate study, DeShaw interviewed Somali patients and those familiar with Somali culture in Minnesota. Their results similarly suggested that a fatalistic belief in disease as the will of God can pose a barrier to preventive care. ${ }^{[50]}$

\section{Ethical and/or cultural challenges within the clinical} arena stemming from Islamic values or practices

Several studies referenced cultural challenges or ethical dilemmas posed to clinicians by Muslim patients. The sources of ethical dilemmas or cultural conflicts often were patients' attempts to adhere to Islamic ethico-legal guidelines, or their different interpretations of health or lack of health. Responses on the part of the health-care provider, or health-care system, to these challenges can influence subsequent health care-seeking behaviors, as is discussed in greater detail in the upcoming sections.

As referenced above, in the study of Somali women, Beine et al. suggested that the provision of contraception by clinicians is challenged as this sample of women did not view pregnancy as a potentially unwanted condition, but rather "a blessing from God." ${ }^{[47]}$ Jan and Smith report in their study about Pakistani families, as do Morioka-Douglas et al. in their study of Afghan-Americans, that the conceptualization of health among individuals included prominent religious conceptions, such as "being on the right path" (i.e., spiritual health). ${ }^{[43,48]}$ Islamic practices may therefore be seen as legitimate interventions against illness. These findings suggest that adequately meeting the expectations of patients who view health and healing in from a religious context may challenge health-care providers because conventional treatments might be viewed by patients as unnecessary. 


\begin{tabular}{|c|c|c|c|c|}
\hline Reference & Study context & Respondent sample & Methods & $\begin{array}{l}\text { Findings pertaining to the } \\
\text { conceptual model }\end{array}$ \\
\hline $\begin{array}{l}\text { Amer and } \\
\text { Hovey }\end{array}$ & $\begin{array}{l}\text { US convenience } \\
\text { sample: } 19 \text { states } \\
\text { and the District } \\
\text { of Columbia } \\
\text { represented. }>20 \% \\
\text { from California and } \\
\text { Texas }\end{array}$ & $\begin{array}{l}\text { I } 20 \text { early immigrant and } 2^{\text {nd }} \\
\text { generation Arab-American } \\
\text { adults. Nearly a quarter of } \\
\text { Egyptian origin with others } \\
\text { from Lebanon, Iraq, Libya, } \\
\text { Jordan, Saudi Arabia, Sudan, } \\
\text { Syria, Tunisia, and Yemen }\end{array}$ & $\begin{array}{l}\text { Web-based survey was } \\
\text { conducted to examine } \\
\text { sociodemographic differences } \\
\text { in acculturation patterns } \\
\text { among early immigrant } \\
\text { and second-generation } \\
\text { Arab-Americans and how that } \\
\text { varies among different religious } \\
\text { communities }\end{array}$ & $\begin{array}{l}\text { Muslim values may portend } \\
\text { poor integration with the } \\
\text { broader society. Findings } \\
\text { suggest that Islam may influence } \\
\text { coping with acculturative stress. } \\
\text { Among Muslims, relative to } \\
\text { Christians, there was no } \\
\text { relation between integration } \\
\text { and mental health, and greater } \\
\text { religiosity was associated with } \\
\text { better family functioning and } \\
\text { lower depression prevalence } \\
\text { (model principle 6) }\end{array}$ \\
\hline Anuforo et al. ${ }^{[59]}$ & $\begin{array}{l}\text { Essex County, New } \\
\text { Jersey }\end{array}$ & $\begin{array}{l}50 \text { adult males and females } \\
\text { from three main Nigerian } \\
\text { ethnic tribes: Igbo, Yoruba, } \\
\text { Hausa }\end{array}$ & $\begin{array}{l}\text { Observed participants to gain } \\
\text { insight into the meanings, } \\
\text { beliefs, and practices of female } \\
\text { circumcision among three } \\
\text { Nigerian tribes in the United } \\
\text { States and Nigeria }\end{array}$ & $\begin{array}{l}\text { As Muslim jurists condone } \\
\text { female genital cutting, Islamic } \\
\text { behavioral practice may } \\
\text { enable the practice, thereby } \\
\text { influencing gynecologic health and } \\
\text { perinatal outcomes } \\
\text { (model principle 6) }\end{array}$ \\
\hline Beine et al. ${ }^{[4]}$ & $\begin{array}{l}\text { San Diego County, } \\
\text { California }\end{array}$ & $\begin{array}{l}\text { I } 4 \text { adult Somali Muslim } \\
\text { women who have received } \\
\text { prenatal care in the United } \\
\text { States }\end{array}$ & $\begin{array}{l}\text { Focus groups interviews } \\
\text { conducted to explore the belief } \\
\text { and attitudes toward prenatal } \\
\text { care among Somali women in } \\
\text { San Diego, particularly in regard } \\
\text { to their perinatal experiences } \\
\text { following immigration }\end{array}$ & $\begin{array}{l}\text { The preference for same-sex } \\
\text { providers, as well as providers } \\
\text { who are conservative with } \\
\text { respect to indicating cesarean } \\
\text { section may guide Somali perinatal } \\
\text { health choices. } \\
\text { Islamic restrictions on smoking } \\
\text { and drinking, both behaviors that } \\
\text { are health compromising, may } \\
\text { improve outcomes. Somali Muslim } \\
\text { women had generally negative } \\
\text { attitudes toward contraception, } \\
\text { as they perceive pregnancy to } \\
\text { be a gift from God } \\
\text { (model principles } 2 \text { and 5) }\end{array}$ \\
\hline Carroll et al..$^{[20]}$ & $\begin{array}{l}\text { Rochester, } \\
\text { New York }\end{array}$ & $\begin{array}{l}34 \text { adult Somali refugee } \\
\text { women }\end{array}$ & $\begin{array}{l}\text { Individual interviews } \\
\text { conducted to learn more about } \\
\text { participant's health experiences } \\
\text { in order to improve health care } \\
\text { for Somali women }\end{array}$ & $\begin{array}{l}\text { Islamic behavioral restrictions } \\
\text { promote healthy behaviors by } \\
\text { limiting risk behaviors. } \\
\text { Spiritual worship may improve } \\
\text { coping with poor health } \\
\text { states and support healthy living. } \\
\text { Muslims may rely on adjuvant } \\
\text { religious therapy, which may delay } \\
\text { or limit health seeking } \\
\text { (model principles } 4 \text { and } 5 \text { ) }\end{array}$ \\
\hline Davidson et al. ${ }^{[51]}$ & $\begin{array}{l}\text { Scripps Mercy } \\
\text { Hospital, San } \\
\text { Diego, California }\end{array}$ & $\begin{array}{l}22 \text { people from the following } \\
\text { subgroups: Muslim, Baha'i, } \\
\text { Catholic, Protestant, Jewish, } \\
\text { Buddhist, Mormon, Jehovah's } \\
\text { Witness, Latino, Filipino, } \\
\text { Chinese, African-American }\end{array}$ & $\begin{array}{l}22 \text { semi-structured qualitative } \\
\text { interviews were conducted } \\
\text { to identify patient and family } \\
\text { needs specifically related to } \\
\text { an in-hospital birth or death } \\
\text { and to perform a gap analysis } \\
\text { between identified needs and } \\
\text { the current hospital practice }\end{array}$ & $\begin{array}{l}\text { Gaps challenging the comfort } \\
\text { of Muslim patients in the care } \\
\text { setting may limit health seeking } \\
\text { behavior (model principles } \\
2,3 \text {, and } 5 \text { ) }\end{array}$ \\
\hline DeShaw $^{[50]}$ & Minnesota & $\begin{array}{l}\text { I5 men and I } 5 \text { women who } \\
\text { are Somali, familiar with the } \\
\text { Somali culture, and/or familiar } \\
\text { with the health-care needs of } \\
\text { Somalis }\end{array}$ & $\begin{array}{l}\text { Qualitative interviews } \\
\text { were conducted to better } \\
\text { understand the way Somalis } \\
\text { view health care and the } \\
\text { reasons why they rely on the } \\
\text { ED rather than clinics for care }\end{array}$ & $\begin{array}{l}\text { Religiously derived fatalism may } \\
\text { be a barrier to early action and } \\
\text { preventive care (model principle I) }\end{array}$ \\
\hline
\end{tabular}




\section{Table I: Contd...}

\begin{tabular}{lll}
\hline Reference & Study context & Respondent sample \\
\hline Ghaemi-Ahmadi $\left.{ }^{[5]}\right]$ & $\begin{array}{l}\text { US convenience } \\
\text { sample }\end{array}$ & $\begin{array}{l}\text { I50 immigrant mothers } \\
\text { residing in California } \\
\text { but originally from Iran, } \\
\text { Afghanistan,Vietnam, } \\
\end{array}$ \\
& & $\begin{array}{l}\text { Cambodia, or Laos and were } \\
\text { eligible for WIC }\end{array}$ \\
& \\
& & \\
Hoodfar and & McGill hospital & 200 couples of Middle Eastern \\
Teebi ${ }^{[39]}$ & patients in Canada & origin
\end{tabular}

Teebi ${ }^{[39]}$

Inhorn $\mathrm{MC}$ and

Fakih $\mathrm{MH}^{[69]}$
IVF clinic in Dearborn, Michigan
250 Arab men presenting for infertility diagnosis and treatment

\section{Islam and \\ Johnson ${ }^{[56]}$}

Jan and Smith ${ }^{[43]}$

Johnson et al. ${ }^{[4]}$

Midwestern US city
Western Canada

50 adult South Asian women of whom were Muslim

43 Lebanese-American Muslims living in the United States of America

Dearborn, Michigan
480 Muslim Arab-American adolescents between the $7^{\text {th }}$ and $12^{\text {th }}$ grades

4 immigrant Pakistani families

San Francisco Bay Area
5 adult Muslim women for interviews; I5 adult Muslim women in focus group
Methods

Formal interview using a survey questionnaire was conducted to explore the social, cultural, and economic factors associated with breastfeeding practices of Persian and Southeast Asian immigrant mothers

Examined genetic profiles of participants to analyze the rates of in-breeding and the effects of it

Qualitative study using semi-structured reproductive histories and open-ended ethnographic interviews to compare barriers to infertility care among African-Americans and Arab-Americans

Cross-sectional surveys to examine smoking prevalence, the associations of known smoking risk factors, religious and cultural influences with adolescents' susceptibility to smoking and experimentation with cigarettes Interviews were conducted to determine the meaning of "staying healthy" as experienced by immigrant Pakistani families living in the United States

Qualitative, open-ended interviews were conducted to explore the explanations and ideas of breast cancer South

Asian women held

Ethnonursing research methods were used that include: Observation, in-depth interviews, and participation with the people in their natural or familiar environment in order to analyze the meanings and experiences of care for Lebanese-Muslims as influenced by cultural context

Focus group interviews conducted to examine the impact of religious and cultural values on health-care behavior of Muslim women from immigrant backgrounds, particularly with regard to cervical cancer screening and to determine whether these women would welcome discussing values and beliefs regarding sexuality and reproductive health
Findings pertaining to the conceptual model

Faith-based injunctions to breastfeed may improve perinatal and maternal health (model principle 4)

As Muslim jurists condone consanguineous marriage, Islamic behavioral practice may enable the practice, thereby influencing risk for genetic diseases (model principle 6) Islamic values may help in rationalization of the stress of infertility. Islamic law may pose a barrier for either adoption or donor gamete utilization which may limit care choices. Medical treatment for infertility may be seen as a religious obligation (model principle 2) Islamic practice may curb teen smoking behavior (model principle 4)

Religiously derived meanings of health include spiritual health. Islam places a premium on spiritual, mental, and physical health maintenance (model principle I)

External locus of control and perceptions of risk may be potential influences on health-seeking behavior among Muslims (model principles I and 5)

Alternative conceptions of disease causation, such as the "evil eye," may provide explanations for lack of health among Muslims. Accommodating Muslim religious practices among care providers may be particularly important to improving the Muslim health-care experience (model principles I and 2)

Islamically based modesty may play an important role in provider preference among Muslim women. There is a perceived value differences between the Western medical system and Muslim patients. Discomfort with gynecologic care, based on Islamically based attitudes, can negatively deter health seeking among young Muslim women in general (model principles 2, 3, 5, and 6) 


\section{Table I: Contd...}

\begin{tabular}{|c|c|c|c|}
\hline Reference & Study context & Respondent sample & Methods \\
\hline $\begin{array}{l}\text { Morioka-Douglas } \\
\text { et al. }{ }^{[48]}\end{array}$ & Fremont, California & $\begin{array}{l}9 \text { leaders of an Afghan elders } \\
\text { group }\end{array}$ & $\begin{array}{l}\text { Focus group conducted to } \\
\text { increase the information } \\
\text { available for clinicians and } \\
\text { educators to care for, and } \\
\text { educated others to care for, } \\
\text { elders from Afghan background } \\
\text { more effectively }\end{array}$ \\
\hline
\end{tabular}

Findings pertaining to the conceptual model

There may be differential interpretations of health within the context of Islamic adherence. Islamically based interpretations of disease etiology may inform health decisions of Muslim patients. Prayer and religious devotion may serve as a perceived means to healing among Muslims. There may be salutatory effects of ritual ablution, prayer, fasting, and abstinence from drinking and pork. Provider preferences are rooted within religiously proscribed gender interaction guidelines, and this preference may influence health-seeking behaviors (model principles I, 2, 4, and 5) Islam may influence expectations with regard to appropriate care and treatment. Religious insensitivity and overt discrimination may pose barriers to health-seeking behavior among Muslim women in the perinatal context (model principles 3, 5, and 6)

Discusses the perinatal health effects of Ramadan fasting (model principle 4)

Focus group interviews wer conducted to study the practice of Ramadan among pregnant Muslim women in Michigan

Shah et al. ${ }^{[49]} \quad$ New York City

36 Arab-American immigrant women and men

Focus group discussions were conducted in Arabic to better understand the health care and cancer knowledge, attitudes, and beliefs of Arab-American immigrants

\section{Simpson and} Carter $^{[53]}$
Rural Southeastern area in the US
7 foreign-born Muslim women

Interviews were conducted to study encounters of Muslim women with health-care providers in a rural area and to present a clearer picture of how Muslim women perceive health-care interactions as a baseline understanding to facilitate the development of culturally and religiously sensitive health-care practices
Discrimination may obstruct health-seeking behavior among Muslims. Religiously based differential interpretations of health, disease, and treatment among Muslims are also discussed (model principles 3 and 5)

Discusses Islamically rooted provider preference and subsequent interactions with the health system, which may limit health seeking among Muslims. In particular, Islamically derived modesty may inhibit standard of care gynecologic practices (model principles 2 and 6)
Religious prohibitions against, or recommendations for, certain therapeutics also influence clinical encounters. In a study of Arab men presenting to an infertility clinic in Michigan, negotiating through Islamic ethico-legal codes proved to be challenging for providers as religious law limited treatment options for infertility-specifically adoption and donor gamete utilization. In a separate interview study of multiple religious groups, Davidson et al. noted that Muslim respondents reported preferences for decreased sedatives at the end of life based on religious sentiments, a preference that may pose a challenge to providers who aim to relieve suffering and pain near the time of death. ${ }^{[51]}$

In an attitudinal study relating to cervical cancer screening, Muslim respondents highly valued modesty and perceiving gynecological examinations as a threat to both modesty and the virginity of unmarried women. The authors of this study posit that these views can problematize routine cervical care and cancer screening. ${ }^{[52]}$ Simpson and Carter reported similar findings in an interview study of immigrant 
Muslim women living in rural communities as respondents reported that Islamic conceptions of modesty and requests for same-sex providers were not adequately met by the health-care system. ${ }^{[53]}$ Findings from Morioka-Douglas et al. and multiple other studies confirm this strong preference for same-sex providers shared by both Muslim women and men. ${ }^{[44,47,48,52,53]}$ Providing and assuring same-sex health-care providers may pose a challenge within the clinical space, and the extent to which this value is accommodated may influence downstream health care-seeking behaviors.

Several studies report on Islamic values that present clinical challenges within the clinical setting. ${ }^{[4,51]}$ For example in an assessment of maternal health needs, Muslim women reported feeling their needs for privacy and modesty and their preferences for same-sex providers, halal food (food-particularly meat-prepared in accordance to Muslim law), and information regarding newborn circumcision were not met by the health-care system. ${ }^{[4]}$ Adequately assessing and meeting expectations of Muslim patients may therefore pose unmet challenges and potentially influence future health care-seeking behavior.

Fasting also poses a unique potential clinical challenge for Muslim patients. A study among Muslim women in Michigan found that many women continue to fast during the month of Ramadan while pregnant. In Reitmanova's aforementioned study, women reported an unmet need for guidance on how to fast safely while pregnant. This points to an unmet need on guidelines for safe practices for healthy women whose fasting poses no harm to either themselves or their fetus. As the religious practice of fasting has important health consequences, particularly in those who have compromised health or are pregnant, fasting may pose a further clinical challenge on providers to offer appropriate medical advice while respecting religious rituals. ${ }^{[4,54]}$

Perceived discrimination due to, or a lack of cultural accommodation of, religious values or practices in the clinical realm

When Islamic values and ethico-legal regulations as adopted by Muslim patients enter the clinical realm, patient expectations, preferences, and needs elicit responses from the individual health-care provider at the micro level and the health-care system at the macro level. Mechanistically, if these needs are left unmet, a lack of cultural accommodation may ensue, and such a response may be perceived by patients to be discriminatory. This response may then influence future Muslim health care-seeking behaviors. Presenting one's Muslim identity through external appearance can also elicit negative interactions within the health-care system, potentially affecting health care-seeking behaviors.
Three studies commented on perceived discrimination within the health-care system. Shah and colleagues interviewed Arab-American immigrants in New York regarding their health-care attitudes. The respondents noted that within the health-care system, women wearing the hijab, the Muslim headscarf, were presumed to be ignorant, were at times refused care, and were assumed to have abusive husbands. ${ }^{[49]}$ In Reitmanova's study, women reported a pervasive lack of cultural sensitivity and several reported discrimination in the hospital. They reported that providers felt Muslim women as "stupid" and misinterpreted their concern for modesty as shame for their bodies. ${ }^{[4]}$

As illustrated in studies by both Davidson et al. and Reitmanova and Gustafson, Muslim patients may perceive multiple unmet needs, and by relation, a lack of cultural accommodations in the clinical realm. This perceived lack of cultural accommodations can influence future health care-seeking behavior, as patients may be reticent to present to health-care providers if they have felt uncomfortable in the clinical space in the past. ${ }^{[44,51]}$

Health practices rooted within the Islamic tradition Multiple studies suggest that Islamic teachings influence Muslim health behaviors. With regard to mechanisms, both differential conceptions of health or lack of health and Islamic ethico-legal regulations may influence the means by which Muslims attempt to keep healthy or become healthy when ill. For example, religious practices may be viewed to have healing qualities and religious prohibitions may lower the incidence of risky health behaviors. These health behaviors, in and of themselves, may influence health differences between Muslims and non-Muslim groups by limiting disease risks among the Muslim population. On the other hand, by acting as competing means of treatment, these health behaviors may also lead to health inequities by influencing the duration from disease onset to when allopathic health care is sought (further discussed in the next section).

Several studies, highlighted above, note that Muslims viewed Islamic practices as health promoting. At times, some use particular practices for therapeutic purposes. In several studies, respondents identified religious practices such as prayer, the recitation of the Qur'an, and supplication to God as having physical and psychological therapeutic values. ${ }^{[20,43,48]}$ In a study on attitudes toward breastfeeding, Irani respondents cited their faith as motivation for breastfeeding their children, thereby promoting health among their infants. ${ }^{[55]}$

While these practices are health promoting, still others are conversely risk mitigating. The aforementioned 
studies, along with others, have strongly considered the influence of Islamic practice on health risk behaviors. Most commonly, Islamic restrictions against smoking and alcohol consumption were cited by respondents in several studies as health promoting, potentially leading to differential health risk between Muslim adherents and others. ${ }^{[20,48,56]}$

\section{Patterns of health care seeking based on Islamic values}

From the studies reported above, it appears that Muslim health care-seeking patterns can be influenced by Islamic teachings in several ways. Conceptions of health and lack of health based on Islamic theology may directly or indirectly influence health-care utilization, as perceiving religious practices to have intrinsic healing qualities-and therefore as viable recourse to allopathic care-may lead to delayed health care seeking. Similarly, if lack of health is perceived to be of spiritual etiology, such as a punishment for lack of faith or past sins, these interpretations may compel one to seek spiritual counsel or remedy in lieu of allopathic treatments, also potentially influencing health care-seeking patterns.

Lastly, Islamic values and ethical guidelines may pose ethical conflicts or cultural challenges within the health-care system, and responses to these challenges may further influence health care-seeking behaviors. For example, an Islamic conception of modesty may lead Muslim patients to desire same-sex health-care providers. ${ }^{[22]}$ Such a stance may be challenging to the health-care system, but if left unaccommodated, may affect downstream health care-seeking patterns.

As mentioned earlier, several studies' participants noted that perceived health benefits from Islamic practices may influence both the decision to and the point in illness progression at which they seek allopathic care. The Islamic value of modesty was reported to result in a strong predilection for same-sex providers among both male and female Muslim respondents across multiple studies. This, in turn, may influence health care-seeking patterns, as a failure by the health system to accommodate these expectations may result in delayed health seeking. ${ }^{[50-53,57]}$ For example in Matin's study, women reported low participation in pap smears due to conceptions of modesty that were not accommodated. ${ }^{[52]}$ Another common theme was that God decreed illness and cure, and that personal behavior may have little influence on illness progression or cure. ${ }^{[41,49,50]}$ Manifestations of an external locus of control through such fatalistic practices or an initial, exclusive reliance on spiritual or religious treatment may lead to delays in seeking allopathic health care. Finally, gaps challenging the comfort of Muslim patients in the clinical care setting may limit health care-seeking behavior, as noted by Davidson and Reitmanova and Gustafson. ${ }^{[44,50]}$

Adverse health exposures due to having a Muslim identity

Adopting a visible Muslim identity may influence health through health-compromising exposures outside of the health-care system such as social discrimination and abuse. On the other hand, being a Muslim may create the possibility of a health risk exposure where Islamic law might condone behaviors that pose health risks. For example, in a focus group study of immigrant Arab-Americans, societal discrimination was reported to influence health. The women in the sample commented that wearing the hijab in public lead to discrimination, verbal abuse, and at times, physical violence that had negative influences on their physical and mental health. ${ }^{[49]}$ These sorts of experiences can result in stress reactions, poorer mental health outcomes, and the adoption of maladaptive coping mechanisms. ${ }^{[58]}$

Islamic law does not prohibit certain forms of consanguineous marriage; while there is a Prophetic statement recommending marriages outside of close lineal circles, marrying first cousin relations is not categorically prohibited. This religious permissiveness may in effect potentiate disease risks. Respondents in several studies commented on these and other religious practices and their influence upon health. ${ }^{[39,59]}$

The literature about ecologic influences particular to the Muslim experience also focused on the issues of acculturative stress. One study assessed differences in acculturative stress and family functioning among Muslim and Christian Arabs, finding that despite being less integrated into American society, Muslims had similar levels of acculturative stress. Increased religiosity was predictive of lower depression rates and better family functioning among Muslims. ${ }^{[60]}$

\section{DISCUSSION}

This study is the first, of which we are aware, to systematically review the extant empirical medical literature to infer relationships between Islamic values, Muslim practices and identity, and potential health inequities. From this review, we constructed a model that incorporates domains of Islamic influence both within and outside the health-care system, highlighting mechanisms by which a Muslim identity may contribute to health differences and health-care inequities.

Outside of the health-care system, Muslim identity and practice may yield health inequities through several mechanisms. Islamic theology influences beliefs about 
health and lack of health that in turn lead to the adoption of health behaviors to maintain health or become healthy when ill. These Islamically informed health behaviors impact health-care utilization as religious practices might be used primarily or in lieu of allopathic treatment, or can be used secondarily when allopathic treatments are ineffective, or might be used in a complementary fashion. The downstream results of such health behaviors and alternative health care-seeking patterns among Muslims may generate health inequities between North American Muslims and the general population.

Within the health-care system, Islamic values and ethico-legal considerations may pose cultural challenges and ethical dilemmas in the clinical sphere. The interplay between these challenges and Muslim patient expectations may influence future health by modulating health care-seeking behaviors: if the health-care system's response to this challenge is perceived as discriminatory, downstream health care-seeking behavior may be negatively impacted. These altered patterns may, in turn, influence health-care outcomes. As an illustrative example, Islamic conceptions of modesty may lead a Muslim patient to request a same-sex health-care provider. If this perceived need is met, it may encourage that patient to seek medical care promptly when ill in the future. On the other hand, if the need is unmet or if the patient perceives discrimination, a negative pattern of health care seeking may ensue, where s/he delays seeking medical care, or relies more heavily upon religious-based treatments in lieu allopathic treatment. Either response from the health-care system can thus influence patient behavior, and may therefore yield health inequities [Figure 1].

Although we built our model from the existing literature about Islam, Muslim identity and practices, and health inequities, it is plausible that similar mechanisms may mediate relationships between other religious groups and health differences. Therefore, our model may be applicable to other religious traditions such as Orthodox Judaism where religious practice is rooted within textual interpretation, and where the modern health-care system is challenged to meet needs derived from this religious identity (i.e., Kosher food and Sabbath elevator). As such, our systematic review has some clear limitations derived from the extant literature itself, and from the process of model construction that we highlight below.

\section{Methodological limitations within the extant literature}

There are several limitations to the extant literature about Islam and Muslim health that challenge our understanding of the relationships between these constructs. First, few studies have quantitatively assessed the relationship between religiosity and Muslim health behaviors and outcomes. Without such studies, one cannot understand the extent to which a particular belief, values, or practice impacts health behaviors and outcomes. Another limitation is that few studies have included data about non-Muslims to allow for comparison between Muslim and non-Muslim groups, thus specificity about what health disparities exist remains relatively unknown. Moreover, the majority of empirical studies in the extant literature have relied on convenience samples in singular locations that largely exclude nonimmigrant American Muslims. Consequently, the generalizability of these studies is suspect.

Given the first two aforementioned limitations-that few studies utilize quantitative analytic approaches and/or few compare data between Muslims and non-Muslim respondents-the extant literature poses important hypotheses about health inequities between Muslim and non-Muslim populations, but may be poorly equipped to substantiate them. In the absence of quantitative analyses of datasets including information about Muslim and non-Muslim respondents, it remains impossible to identify or quantify population-level differences in health between Muslim and non-Muslim groups. Moreover, while qualitative analyses may yield important insights about mechanisms that may function to influence the health of Muslims, without quantitative analysis, these cannot be verified to operate on the population level.

Overreliance on nondiverse convenience samples in singular locations poses another relevant limitation. The extant literature has informed our understanding of potential mechanisms that might relate Islam and health. However, as a result of sampling only one ethnic group within the Muslim population, these studies may be confounded by particularities arising from ethnic or cultural features independent of Islamic practice or Muslim identity. Relatedly, particular cultural interpretations of the religion render these mechanisms nongeneralizable to the overall Muslim experience in North America. For example, the practice of female genital cutting among Somali women is not being common to other ethnic groups in the North American Muslim population. ${ }^{[59]}$ Another important point to consider is that the majority of studies sampled immigrant Muslims whereas a growing proportion of the Muslim population is native to North America. As differences in health metrics between native and foreign-born minorities have demonstrated, data from largely foreign-born samples may not generalize to native-born Muslim populations. ${ }^{[61,62]}$ Finally, the plurality (35\%) of Muslims in the US are African-Americans. ${ }^{[63]}$ None of the studies reviewed above 
collected data from African-American respondents, posing a substantial limitation to our understanding of the mechanistic influences of Islamic practice and Muslim identity on the health of this particular Muslim subgroup.

\section{Limitations of the conceptual model}

Two researchers primarily constructed our model with discrepancies resolved through consensus meetings and input from the collaborative team. Being that both authors are practicing Muslims who have familiarity with the Islamic law, the model differentiates between Islam as a textual tradition and Muslim practices that interpret these texts into a living culture. An Islamic practice is one that can be said to originate from normative Islamic teachings, for example, the recitation of the Qur'an as health promoting or the prohibition of alcohol consumption. A Muslim practice is one that does not have a specific origin from the religious texts and sources of law; however, may find substantiation within the lived tradition, for example, consanguineous marriage. As such, our synthetic review is akin to a qualitative review emphasizing validity over generalizability. Utilizing multiple reviewers with content expertise in Islam and Muslim health-care behaviors enhances the internal validity and conceptual rigor of our model. However, external validity and applicability to other groups require prospective quantitative assessment.

Limitations of our model are linked to limitations of the studies themselves. In other words, our model is also limited by the paucity of quantitative measures linking Islam to health differences. To assess the influence of Islam upon human behavior, metrics of Islamic religiosity may be necessary. None of the studies we assessed measured Islamic religiosity across participants. This echoes a profound need for organically constructed, validated metrics of religiosity to assess a Muslim population, as there are inherent limitations to some constructed scales (given, for example, poor time stability of religiousness over one's lifetime). ${ }^{[64,65]}$ Particularly when considering health-care behaviors, lack of health may modulate one's connection to their faith and faith practices, and therefore, the conceptual exercise of linking religiosity to health behaviors is challenging. This limitation particularly bears significance for each of the associations within our model, as they presuppose a relationship between religiosity and outcomes of interest. While our review did find mechanisms that might underlie relations between Islam, Muslim practice, and health differences, validating each link will require systematic assessment through quantitative implements.

Moreover, given that our model was constructed from a systematic review of the medical literature, influences outside of those mentioned in these studies may have been systematically excluded. Illustratively, several studies suggest that understanding the influence of Islam on American Muslim health may be enhanced by understanding the roles of religious leaders who serve this faith community since they serve as sources of Islamic knowledge, interpret how Islam informs health-care provision and behaviors, and serve as religious adjudicators on ethical challenges around medical care. ${ }^{[6-68]}$ Yet the influence of Islamic religious leaders and mosques in distilling Muslim health-care behaviors or in health promotion was not assessed in the captured literature. Lastly as with any systematic review, our findings are based only on those studies we were able to capture. Our search strategy may have excluded studies that were pertinent to this review, especially those in languages other than English, or those that were not indexed in Medline.

\section{CONCLUSION}

From a systematic literature review, we derived an exploratory conceptual framework featuring mechanisms that relate religion to health inequities. Several constructs that may mediate differences in health between Muslims and non-Muslims emerged: (1) Interpretations of health and/or lack of health based on Islamic theology; (2) Ethical and/or cultural challenges within the clinical arena stemming from Islamic values or practices; (3) Perceived discrimination due to, or a lack of cultural accommodation of, religious values or practices in the clinical realm; (4) Health practices rooted within the Islamic tradition; (5) Patterns of health care seeking based on Islamic values; and (6) Adverse health exposures due to having a Muslim identity.

From this review and conceptual framework, we suggest several avenues for future research. First, investigators interested in the health of Muslims in North America might pursue population-representative, prospective studies examining the health and well-being of Muslims in North America. Second, future studies about Muslim health should include data about non-Muslim referent groups that will allow for cross-religious comparison. Third, quantitative analyses among population-representative datasets of the Muslim community are needed both to clarify relationships between Muslim practice, identity, and health, as well as to validate mechanisms that may relate Muslim identity and behavior to health outcome inequities. Finally, specific quantitative scales and metrics developed from, or validated within, Muslim communities are needed to enhance the rigor of investigations regarding associations between Islam and health. 


\section{Acknowledgments}

We thank Drs. Afrah Raza, Shoaib Rasheed, and Hasan Shanawani for assistance with the literature review, and Dr. Abdul El-Sayed for assisting with model generation.

\section{Financial support and sponsorship}

AIP's time and effort was supported by the Robert Wood Johnson Foundation Clinical Scholars Program, and a portion of this work was conducted during AIP's tenure as a Visiting Fellow at the Oxford Centre for Islamic Studies.

\section{Conflicts of interest}

There are no conflicts of interest.

\section{REFERENCES}

1. Bender R, Jöckel KH, Trautner C, Spraul M, Berger M. Effect of age on excess mortality in obesity. JAMA 1999;281:1498-504.

2. Engels F. The Condition of the Working-Class in England in 1844. Harmondsworth: Penguin; 1845.

3. Smith GD, Chaturyedi N, Harding S, Nazroo J, Williams R. Ethnic inequalities in health: A review of UK epidemiological evidence. Crit Public Health 2000;10:375-408.

4. Alexander GR, Kogan MD, Himes JH, Mor JM, Goldenberg R. Racial differences in birthweight for gestational age and infant mortality in extremely-low-risk US populations. Paediatr Perinat Epidemiol 1999;13:205-17.

5. Cooper R, Cutler J, Desvigne-Nickens P, Fortmann SP, Friedman L, Havlik R, et al. Trends and disparities in coronary heart disease, stroke, and other cardiovascular diseases in the United States: Findings of the national conference on cardiovascular disease prevention. Circulation 2000; 102:3137-47.

6. Lu MC, Chen B. Racial and ethnic disparities in preterm birth: The role of stressful life events. Am J Obstet Gynecol 2004;191:691-9.

7. Ward E, Jemal A, Cokkinides V, Singh GK, Cardinez C, Ghafoor A, et al. Cancer disparities by race/ethnicity and socioeconomic status. CA Cancer J Clin 2004;54:78-93.

8. Wise PH, Kotelchuck M, Wilson ML, Mills M. Racial and socioeconomic disparities in childhood mortality in Boston. N Engl J Med 1985;313:360-6.

9. Wong MD, Shapiro MF, Boscardin WJ, Ettner SL. Contribution of major diseases to disparities in mortality. N Engl J Med 2002;347:1585-92.

10. Geronimus AT. Black/white differences in the relationship of maternal age to birthweight: A population-based test of the weathering hypothesis. Soc Sci Med 1996;42:589-97.

11. Geronimus AT. The weathering hypothesis and the health of African-American women and infants: Evidence and speculations. Ethn Dis 1992;2:207-21.

12. Brown TN, Williams D, Jackson J, Neighbors H, Torres M, Sellers SL, et al. Being black and feeling blue: The mental health consequences of racial discrimination. Race Soc 2000;2:117-31.

13. Hovey JD, King CA. Acculturative stress, depression, and suicidal ideation among immigrant and second-generation Latino adolescents. J Am Acad Child Adolesc Psychiatry 1996;35:1183-92.

14. Finch BK, Vega WA. Acculturation stress, social support, and self-rated health among Latinos in California. J Immigr Health 2003;5:109-17.

15. Lee J, Koeske GF, Sales E. Social support buffering of acculturative stress: A study of mental health symptoms among Korean international students. Int J Intercult Relat 2004;28:399-414.

16. Wrobel NH, Farrag MF, Hymes RW. Acculturative stress and depression in an elderly Arabic sample. J Cross Cult Gerontol 2009;24:273-90.
17. Herman AA. Toward a conceptualization of race in epidemiologic research. Ethn Dis 1996;6:7-20.

18. Merchant A, Husain SS, Hosain M, Fikree FF, Pitiphat W, Siddiqui AR, et al. Paan without tobacco: An independent risk factor for oral cancer. Int J Cancer 2000;86:128-31.

19. Ahmed S, Atkin K, Hewison J, Green J. The influence of faith and religion and the role of religious and community leaders in prenatal decisions for sickle cell disorders and thalassaemia major. Prenat Diagn 2006;26:801-9.

20. Carroll J, Epstein R, Fiscella K, Volpe E, Diaz K, Omar S, et al. Knowledge and beliefs about health promotion and preventive health care among Somali women in the United States. Health Care Women Int 2007;28:360-80.

21. Al Suwaidi J, Bener A, Suliman A, Hajar R, Salam AM, Numan MT, et al. A population based study of Ramadan fasting and acute coronary syndromes. Heart 2004;90:695-6.

22. Padela AI, Rodriguez del Pozo P. Muslim patients and cross-gender interactions in medicine: An Islamic bioethical perspective. J Med Ethics 2011;37:40-4.

23. Yehya NA, Dutta MJ. Health, religion, and meaning: A culture-centered study of Druze women. Qual Health Res 2010;20:845-58.

24. Koenig HG. Research on religion, spirituality, and mental health: A review. Can J Psychiatry 2009;54:283-91.

25. Koenig HG. Religious practices and health: Overview. Washington DC: The Heritage Foundation 2008.

26. Larson DB, Larson SS, Koenig HG. Mortality and religion/spirituality: A brief review of the research. Ann Pharmacother 2002;36:1090-8.

27. Obama B. Remarks by the President on a New Beginning. Cairo, Egypt: 2009.

28. Smith TW. The Muslim population of the United States: The methodology of estimates. Public Opin Q 2002;66:404-17.

29. CAIR: U.S. Muslims to Count Population, Council on American-Islamic Relations; 2015. Available from: http://www.cair.com/press-center/ cair-in-the-news/5656-cair-u-s-muslims-to-count-population.html. [Last retrieved on 2017 Aug 07].

30. Demographic Portrait of Muslim Americans, Pew Research Center; 2017. Available from: http://www.pewforum.org/2017/07/26/ demographic-portrait-of-muslim-americans. [Last Retrieved on 2017 Aug 07].

31. Mapping the Global Muslim Population. Pew Research Center; 2009.

32. Ba-Yunus I. Muslims of Illinois, A Demographic Report. Chicago, East-West University; 1997. p. 9.

33. Curlin F. OB-GYNs Approaches to Sexual and Reproductive Health Care: A National Survey, Survey Methodology Report. Chicago, IL, Program on Medicine and Religion; 2010. p. 1-61.

34. Laird LD, de Marrais J, Barnes LL. Portraying Islam and Muslims in MEDLINE: A content analysis. Soc Sci Med 2007;65:2425-39.

35. Gatrad AR, Sheikh A. Hajj: Journey of a lifetime. BMJ 2005;330:133-7.

36. Padela Al. Can you take care of my mother? Reflections on cultural competency and clinical accommodation. Acad Emerg Med 2007;14:275-7.

37. Vu M, Azmat A, Radejko T, Padela AI. Predictors of delayed healthcare seeking among American Muslim women. J Womens Health (Larchmt) 2016;25:586-93.

38. Athar S, Ahmed WD, Amine AR, Fadel HE, Haque M, Nagamia HF, et al. Our position: The position of Islamic medical association of North America on issues of medical ethics. Islamic Medical Association North America 2005.

39. Hoodfar E, Teebi AS. Genetic referrals of Middle Eastern origin in a Western city: Inbreeding and disease profile. J Med Genet 1996;33:212-5.

40. Hutchinson MK, Baqi-Aziz M. Nursing care of the childbearing Muslim family. J Obstet Gynecol Neonatal Nurs 1994;23:767-71.

41. Johnson JL, Bottorff JL, Balneaves LG, Grewal S, Bhagat R, Hilton BA, 
et al. South Asian womens' views on the causes of breast cancer: Images and explanations. Patient Educ Couns 1999;37:243-54.

42. Padela AI, Gunter K, Killawi A, Heisler M. Religious values and healthcare accommodations: Voices from the American Muslim community.J Gen Intern Med 2012;27:708-15.

43. Jan R, Smith CA. Staying healthy in immigrant Pakistani families living in the United States. Image J Nurs Sch 1998;30:157-9.

44. Reitmanova S, Gustafson DL. "They can't understand it": Maternity health and care needs of immigrant Muslim women in St. John's, Newfoundland. Matern Child Health J 2008;12:101-11.

45. Padela AI, Killawi A, Forman J, DeMonner S, Heisler M. American Muslim perceptions of healing: Key agents in healing, and their roles. Qual Health Res 2012;22:846-58.

46. Padela AI, Raza A. American Muslim health disparities: The state of the Medline literature. J Health Dispar Res Pract 2015;8:1-9.

47. Beine K, Fullerton J, Palinkas L, Anders B. Conceptions of prenatal care among Somali women in San Diego. J Nurse Midwifery 1995;40:376-81.

48. Morioka-Douglas N, Sacks T, Yeo G. Issues in caring for Afghan American elders: Insights from literature and a focus group. J Cross Cult Gerontol 2004;19:27-40.

49. Shah SM, Ayash C, Pharaon NA, Gany FM. Arab American immigrants in New York: Health care and cancer knowledge, attitudes, and beliefs. J Immigr Minor Health 2008;10:429-36.

50. DeShaw PJ. Use of the emergency department by Somali immigrants and refugees. Minn Med 2006;89:42-5.

51. Davidson JE, Boyer ML, Casey D, Matzel SC, Walden CD. Gap analysis of cultural and religious needs of hospitalized patients. Crit Care Nurs Q 2008;31:119-26.

52. Matin M, LeBaron S. Attitudes toward cervical cancer screening among Muslim women: A pilot study. Women Health 2004;39:63-77.

53. Simpson JL, Carter K. Muslim women's experiences with health care providers in a rural area of the United States. J Transcult Nurs 2008;19:16-23.

54. Robinson T, Raisler J. "Each one is a doctor for herself": Ramadan fasting among pregnant Muslim women in the United States. Ethn Dis 2005;15:S1-99-103.

55. Ghaemi-Ahmadi S. Attitudes toward breast-feeding and infant feeding among Iranian, Afghan, and Southeast Asian immigrant women in the United States: Implications for health and nutrition education. J Am Diet Assoc 1992;92:354-5.
56. Islam SM, Johnson CA. Correlates of smoking behavior among Muslim Arab-American adolescents. Ethn Health 2003;8:319-37.

57. Luna L. Care and cultural context of Lebanese Muslim immigrants: Using Leininger's theory. J Transcult Nurs 1994;5:12-20.

58. Raza A, Shanawani H, Padela AI. Healthcare disparities in immigrant Muslims in US \& Canada: A systematic literature review 2010.

59. Anuforo PO, Oyedele L, Pacquiao DF. Comparative study of meanings, beliefs, and practices of female circumcision among three Nigerian tribes in the United States and Nigeria. J Transcult Nurs 2004;15:103-13.

60. Amer MM, Hovey JD. Socio-demographic differences in acculturation and mental health for a sample of $2^{\text {nd }}$ generation/early immigrant Arab Americans. J Immigr Minor Health 2007;9:335-47.

61. El-Sayed AM, Galea S. Explaining the low risk of preterm birth among Arab Americans in the United States: An analysis of 617451 births. Pediatrics 2009;123:e438-45.

62. Singh GK, Hiatt RA. Trends and disparities in socioeconomic and behavioural characteristics, life expectancy, and cause-specific mortality of native-born and foreign-born populations in the United States, 1979-2003. Int J Epidemiol 2006;35:903-19.

63. Younis M. Muslim Americans Exemplify Diversity, Potential; 2009. Available from: http://www.gallup.com/poll/116260/ Muslim-Americans-Exemplify-Diversity-Potential.aspx. [Last retrieved on 2010 Nov 12].

64. Amer MM, Hood Jr. RW. Special issue: Part II. Islamic religiosity: Measures and mental health. J Muslim Ment Health 2008;3:1-5.

65. Raiya HA, Pargament K, Stein C, Mahoney A. Lessons learned and challenges faced in developing the psychological measure of Islamic religiousness. J Muslim Ment Health 2007;2:133-54.

66. Ali OM, Milstein G, Marzuk PM. The imam's role in meeting the counseling needs of Muslim communities in the United States. Psychiatr Serv 2005;56:202-5.

67. Freij LS. ES Model: Mobilizing Muslim Imams and Religious Leaders as "Champions" of Reproductive Health and Family Planning. T. E. S. D. Project; 2010.

68. Padela AI, Killawi A, Heisler M, Demonner S, Fetters MD. The role of imams in American Muslim health: Perspectives of Muslim community leaders in Southeast Michigan. J Relig Health 2011;50:359-73.

69. Inhorn MC, Fakih MH. Arab Americans, African Americans, and infertility: Barriers to reproduction and medical care. Fertil Steril 2006;85:844-52. 